\title{
Retrospective Inspection and Dissemination Pattern of Common Metabolic Ailments among Hilly and Tarai Region Goats of Uttarakhand
}

\author{
Alok Singh ${ }^{1 *}$, J.L. Singh ${ }^{1}$, S.K. Rastogi ${ }^{2}$, A.H. Ahmad ${ }^{3}$, N. Arora ${ }^{1}$, D.V. Singh ${ }^{4}$ and M. Batra ${ }^{5}$ \\ ${ }^{1}$ Department of Veterinary Medicine, College of Veterinary \& Animal Sciences, GBPUAT, Pantnagar, INDIA \\ ${ }^{2}$ Department of Veterinary Physiology, College of Veterinary \& Animal Sciences, GBPUAT, Pantnagar, INDIA \\ ${ }^{3}$ Department of Veterinary Pharmacology and Toxicology, College of Veterinary \& Animal Sciences, GBPUAT, Pantnagar, INDIA \\ ${ }^{4}$ Department of Livestock Production Management, College of Veterinary \& Animal Sciences, GBPUAT, Pantnagar, INDIA \\ ${ }^{5}$ Department of Veterinary Phatology, College of Veterinary \& Animal Sciences, GBPUAT, Pantnagar, INDIA
}

"Corresponding author: A Singh; E-mail: aloksinghvet.87@gmail.com

Received: 04 Mar., 2020

Revised: 07 April, 2020

Accepted: 14 April, 2020

\begin{abstract}
Goats are considered as an important animal not in present scenario but also from ancient time. Due to increasing frugal interest of goat farming globally, profound animal husbandry practices are attaining importance under the target of obtaining quality products along with good animal health and welfare. During the transition phase of life, noticeable alterations in the endocrine and metabolic status of the dairy ruminants were registered. Among small ruminants i.e. goat's hypocalcaemia, hypoglycemia/Pregnancy toxemia and hypomagnesaemia are the common metabolic disorders which normally precipitated during metabolic anxiety phase. The present study was conducted during the period of $1^{\text {st }}$ January 2019 to $31^{\text {st }}$ December 2019. During this period we had registered total 957 goats at Kalsi, Chakrata areas of district Dehradun, Chorgalia, Kotabagh, Kaladhungi areas of district Nainital and Shetlai, Pantnagar, Bazpur areas of district Uddham Singh Nagar beside this we had also included the concerned cases from Government Veterinary Hospital Outpatient departments (OPDs) of the above said areas in Uttarakhand. In the present study, we had performed a prevalence study over common occurring metabolic diseases of goats like hypocalcaemia, hypoglycemia/pregnancy toxemia and hypomagnesaemia. Besides this, we had also studied the dissemination pattern of common occurring metabolic diseases on the basis of their age groups and parity.
\end{abstract}

Keywords: Metabolic ailments, prevalence, hypocalcaemia, hypoglycemia, hypomagnesaemia

As per the $20^{\text {th }}$ livestock census, (2019) of India total goat population in the country is 148.88 million and about $27.8 \%$ of the total livestock is contributed by goats, besides this on population basis India holds first position globally. Goats are considered as an important animal not in present scenario but also from ancient time. Due to increasing frugal interest of goat farming globally, profound animal husbandry practices are attaining importance under the target of obtaining quality products along with good animal health and welfare (Celi et al., 2008). Profound goat rearing practices are used to increase the milk yield in goats (Rubino et al., 1995). This ultimately increases the risk of precipitation of peripartum ailments. Drackley (1999) narrated that gestation period and lactogenesis are the two physiological stages during which the individual faces the metabolic anxiety. Transition period or periparturient period is normally defined as the time period 21 days prior to parturition to 21 days post parturition and this time phase is considered as more prone for the precipitation of various metabolic diseases. During this phase of life, noticeable alterations in the endocrine and metabolic status of the dairy ruminants were registered (Radin et al., 2015). As we know that high prolificacy rate of the small ruminants, i.e. goats ultimately increases

How to cite this article: Singh, A., Singh, J.L., Rastogi, S.K., Ahmad, A.H., Arora, N., Singh, D.V. and Batra, M. (2020). Retrospective inspection and dissemination pattern of common metabolic ailments among hilly and Tarai region goats of Uttarakhand. J. Anim. Res., 10(3): 359-364. Source of Support: None; Conflict of Interest: None कs क्ष 
the demand for nutrition during the last third phase of gestation. According to Smith and Sherman (2009) among small ruminants i.e. goat's hypocalcaemia, pregnancy toxemia and hypomagnesaemia are the common metabolic disorders which normally precipitated during metabolic anxiety phase. Various studies have been performed regarding the prevalence of the metabolic diseases among large ruminants in India; however, such prevalence studies about small ruminants are meagre in our country. So due to the availability of meagre findings concerning to prevalence of the metabolic diseases in small ruminants, the present study was conducted with an objective of "Studies on clinical prevalence of commonly occurring metabolic diseases of goats" in Hilly and Tarai region of Uttarakhand in India.

\section{MATERIALS AND METHODS}

\section{Selection criteria of animals and design of the study}

The present study was conducted during the period of $1^{\text {st }}$ January 2019 to $31^{\text {st }}$ December 2019. During this period we had registered total 957 goats at Kalsi, Chakrata areas of district Dehradun, Chorgalia, Kotabagh, Kaladhungi areas of district Nainital and Shetlai, Pantnagar, Bazpur areas of district Uddham Singh Nagar beside this we had also included the concerned data from Government Veterinary Hospital Outpatient departments (OPDs) of the above said areas in Uttarakhand. However, the semi stall-fed pattern of feeding was adopted by the registered goats and the climatic conditions of the said geographical areas were humid subtropical. The total number of goats $(n=957)$ were distributed as $(n=284)$ goats of Hilly regions and $(n=673)$ goats of Tarai region of Uttarakhand. The schematic presentation of the total number of goats registered under various categories during this study is depicted in Fig. 1. In the present investigation, consideration was only made towards the commonly occurring metabolic disorders of goats i.e. hypoglycemia/Pregnancy toxemia, hypocalcaemia and hypomagnesaemia. Blood samples were collected from the registered goats during the transition period (pre \& postpartum accordingly). For biochemical analysis $3 \mathrm{ml}$ blood samples were collected from the jugular vein of each goat following all aseptic precautions and transferred it into the clot activating vials and allowed to clot in slanting position for about one to two hours. Separated serum was harvested gently after centrifugation for 10 minutes at 2,000 to $3000 \mathrm{rpm}$ in a labelled dry eppendorf with the help of micropipette and preserved at $-20^{\circ} \mathrm{C}$ in a deep freezer for further use. Serum estimation of glucose, calcium and magnesium were carried out by using Erba diagnostics Mannheim GmbH, Germany kits as per there protocol and Beta-Hydroxybutyrate (BHBA) was estimated by using specific calorimetric Kits (G- Biosciences,USA). All the registered goats were administered anthelmintics and underwent random faecal sample examination, negative results indicating free of parasitic burden. The incorporation of various goats under a specific metabolic disorder group depended upon the clinical findings and the serum analysis of various relative analytes.

\section{Hypocalcaemia category}

Incorporation of goats under hypocalcaemia category was based on the clinical anomalies such as ataxic, nervous, hyperactive, tremor of the muscles, sternal recumbency, mucus exudates in nostrils, fine muscle twitching of the lips, eyelids, and ears and mental depression. However, serum calcium level less than $6 \mathrm{mg} / \mathrm{dl}$ was considered as positive for hypocalcaemia (Rankins et al., 2002) in the present study.

\section{Hypomagnesaemia category}

Incorporation of goats under hypomagnesaemia category was based on the clinical anomalies such as ataxia, muscle stiffness, hyperexcitability, over-stimulated muscles, extreme leg stiffness, muscle spasms, teeth grinding and tetany. However, serum magnesium level less than 1.5 $\mathrm{mg} / \mathrm{dl}$ was considered as positive for hypomagnesaemia (Rankins et al., 2002) in the present study.

\section{Hypoglycemia/Pregnancy toxemia category}

Incorporation of goats under hypoglycemic/Pregnancy toxemia category was based on the clinical anomalies such as behavioural changes, does normally isolate themselves and appear dull, and depressed, in advance cases neurologic manifestations become evident and does may appear blind, become disoriented and ataxic, reduced feed intake. However, serum glucose level less than $30 \mathrm{mg} / \mathrm{dl}$ 
was considered as positive for hypoglycemia (Gupta et al., 2007) and a serum level of BHBA greater than $0.8 \mathrm{mmol} / \mathrm{l}$ was consider as positive for pregnancy toxemia (Ismail, et al., 2015) in the present study.

\section{STATISTICAL ANALYSIS}

To study the significant differences in the conditions of the diseases among Hilly and Tarai region goats of Uttarakahand, the epidemiological data were subjected to Pearson's chi-square $\left(\chi^{2}\right)$ test.

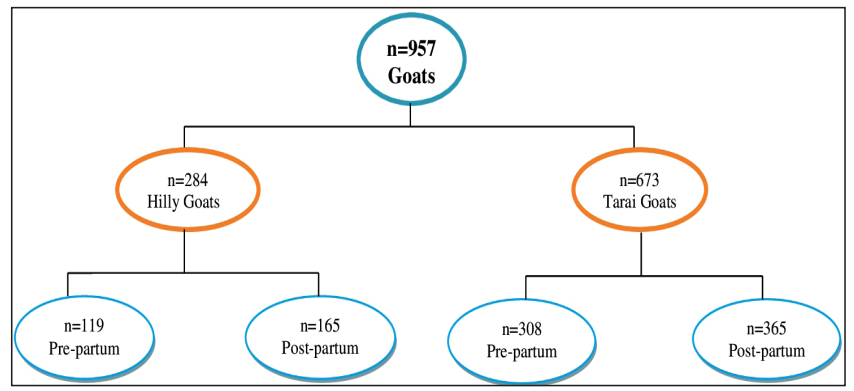

Fig. 1. Schematic presentation of the total number of goats registered under various categories during this study

\section{RESULTS AND DISCUSSION}

\section{Region-wise prevalence}

The findings of present study among the registered preparturient hilly region goats, revealed that $(6.72 \%, 08 / 119)$, $(5.88 \%, 07 / 119)$ and $(4.20 \%, 05 / 119)$ goats were positive for hypoglycemia, hypocalcaemia and hypomagnesaemia respectively. However for hilly region post-parturient goats $(5.45 \%, 09 / 165),(5.88 \%, 07 / 165)$ and $(3.63 \%, 06 / 165)$ goats were positive for hypoglycemia, hypocalcaemia and hypomagnesaemia respectively. Meanwhile among preparturient goats of Tarai region $(6.49 \%, 20 / 308)(2.27 \%$, $07 / 308)$ and $(1.94 \%, 06 / 308)$ goats were found positive for hypoglycemia, hypocalcaemia and hypomagnesaemia respectively and for post parturient goats of Tarai region $(7.94 \%, 29 / 365),(3.01 \%, 11 / 365)$ and $(2.73 \%$, $10 / 365$ ) goats were found positive for hypoglycemia, hypocalcaemia and hypomagnesaemia respectively. Differences in the various metabolic diseases conditions among Hilly and Tarai region goats of Uttarakhand was found non-significant as the Pearson's chi-square $\left(\chi^{2}\right)$ test revealed P-value $>0.05$. Meanwhile, the region-wise prevalence of commonly occurring metabolic diseases, among Hilly and Tarai region goats of Uttarakhand for (Pre-parturient) and (Post-parturient) is graphically depicted in Fig. 2 and 3 respectively.

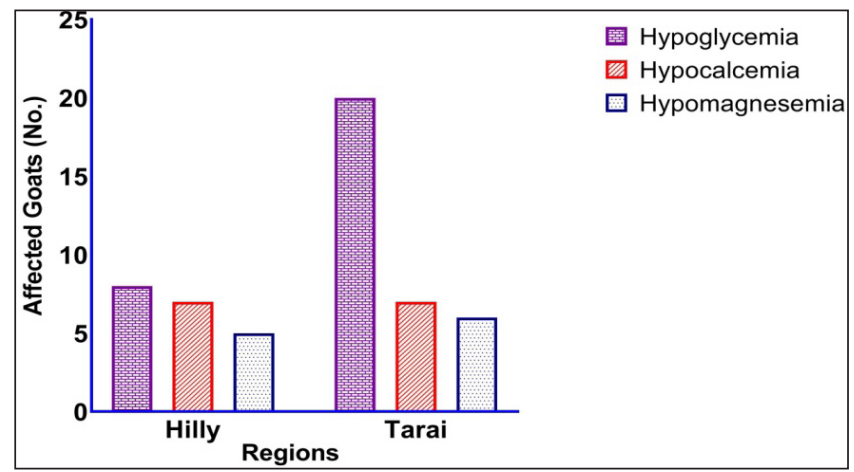

Fig. 2: Prevalence of metabolic diseases among Hilly and Tarai region goats (Pre-Parturient)

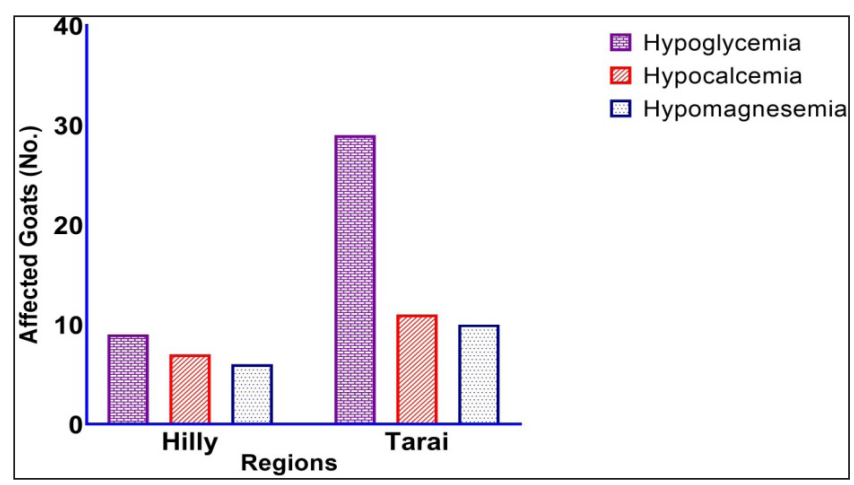

Fig. 3: Prevalence of metabolic diseases among Hilly and Tarai region goats (Post-Parturient)

It is well established that Blood glucose is considered as one of the important parameters of metabolic profile test; that's why it has discernible value during various production diseases and reproductive defects. The concentration of glucose is variable during gestation, lactogenesis and dry period. The variations in glucose level among pregnant and lactating animals affirm that there is the utilization of glucose by fetus and milk yield, which ultimately signifies the importance of glucose administration prior and post parturition and resulted in the scaling down of hypoglycemia / pregnancy toxemia (Ramin et al., 2007). In the present study, during pre-parturient \& post-parturient stage of Hilly and Tarai region goats, we 
found hypoglycemia as $6.72 \%, 5.45 \%, 6.49 \%$ and $7.94 \%$ respectively. Lalitha et al. (2001) has also reported 03\% pregnancy toxemia in pregnant goat however Ismail et al. (2015) reported the prevalence percentage of pregnancy toxemia was $13.3 \%$ in goats. Meanwhile, among large ruminants prevalence of ketosis was claimed as $2-20 \%$. The results of this study were also in corroboration to the previous work of Rook (2000) who claimed that distorted nutritional and feeding managemental factors, can lead to herd outbreak with morbidity rates exceeding $10 \%$ of the does.

Among cows, one of the complex factors that persist at the time of parturition is to maintain the constant level of blood calcium. During the last $3^{\text {rd }}$ week of pregnancy, there is need for the significant amount of calcium for skeleton development by the fetus. Azab and Abdel-Maksoud (1999) and Iriadam (2007) documented similar findings among goats that calcium concentration declined in late pregnancy period, and the minimum value was reported on kidding and the values remained towards the low side for the $1^{\text {st }}$ week of lactation. This observed decline in calcium concentration at late pregnancy period might be due to increased demand for calcium for the development of fetal skeleton. At the time of parturition, due to drainage of the huge amount of calcium into colostrums may lead to decline concentration of blood calcium level in cattle's. However, preservation of calcium equipoise is crucial for various physiological functions like neuromuscular excitability, clotting of blood, and secretion of the hormone. In the present study during pre-parturient \& post -parturient stage of Hilly and Tarai region goats, we found hypocalcaemia as $5.88 \%, 5.88 \%, 2.27 \%$ and $3.01 \%$ respectively. These findings were corroboration to Peter and Peter (2011) recorded less than 5\% of hypocalcaemia in a flock of ewes during pre \& post -parturient stages. However, explorative work of Roche et al. (2000) claimed that incidence of hypocalcaemia in a flock of ewes may be high up to $10 \%$ during late gestation period or during early lactogenesis. In the bony skeleton, somewhat 60 to $70 \%$ of the magnesium normally exists. Meanwhile; soft tissues and extracellular body fluids possess remaining $30-40 \%$. Majority of the enzymes related to the protein, carbohydrate and fat metabolism are magnesium dependent for their activation. In ruminants, the rumen is considered as the main absorption site for magnesium. However, hormone-mediated magnesium metabolism has no indications, while calcium and phosphorus indicates hormone-mediated metabolism. As extensive depletion of magnesium from the extracellular fluid pool may lead to the tetanic condition. In the present study during pre-parturient \& post-parturient stage of Hilly and Tarai region goats, we found hypomagnesaemia as $4.20 \%$, $3.63 \%, 1.94 \%$ and $2.73 \%$ respectively. However, previous explorative works also highlighted that there is $1-3 \%$ of mortality in each year among large and small ruminants due to various affections related to hypomagnesaemia.

\section{Dissemination pattern of common metabolic disorders among Hilly and Tarai region goats, on the basis of various age groups and parity wise}

The findings of the present study revealed that among hilly region goats, age-wise dissemination of hypoglycemic case revealed maximum occurrence among 3-4 years of age group (41.17\%) followed by $4-5$ years of age group $(35.29 \%)$ and $(23.52 \%)$ among $2-3$ years of age group. However, in case of Tarai region goats, maximum dissemination of hypoglycemia was recorded among 4-5 years age group (38.77\%) followed by $3-4$ years age group $(36.73 \%)$ and $2-3$ years age group $(24.48 \%)$ respectively. In the case of hypocalcemic goats, maximum occurrence $(45.85 \%)$ was sought during 4-5 years of age group followed by $(35.71 \%)$ among 3-4 years age group of Hilly goats. Meanwhile, maximum cases (44.44\%) were recorded among 3-4 years age group of Tarai region goats followed by $(33.33 \%)$ among $4-5$ years age group. In case of both Tarai \& Hilly region goats, lowest hypocalcaemic cases were recorded among 2-3 years, age group. The findings of the present study revealed that among hilly region goats, age-wise dissemination of hypomagnesaemia cases revealed maximum occurrence among 4-5 years of age group $(45.45 \%)$ followed by $3-4$ years of age group $(36.36 \%)$ and $(18.18 \%)$ among $2-3$ years of age group.

However, in case of Tarai region goats maximum dissemination of hypomagnesaemia was recorded among 3-4 years age group $(50.00 \%)$ followed by $3-4$ years age group (31.25\%) and 2-3 years age group (18.75\%) respectively. The dissemination pattern of metabolic diseases in Hilly and Tarai region goats of Uttarakhand, based on various age groups is graphically depicted in Fig. 4 and 5 respectively. The findings of present studies revealed that among hilly region goats parity wise 
dissemination of hypoglycemic case revealed maximum occurrence among $2^{\text {nd }}$ parity goats $(41.17 \%)$ followed by $3^{\text {rd }}$ parity goats $(35.29 \%)$ and $(23.52 \%)$ among $1^{\text {st }}$ parity goats. However, in case of Tarai region goats maximum dissemination of hypoglycemia was recorded among $3^{\text {rd }}$ parity goats $(44.89 \%)$ followed by $2^{\text {nd }}$ parity goats $(34.69 \%)$ and $1^{\text {st }}$ parity goats $(20.40 \%)$ respectively.

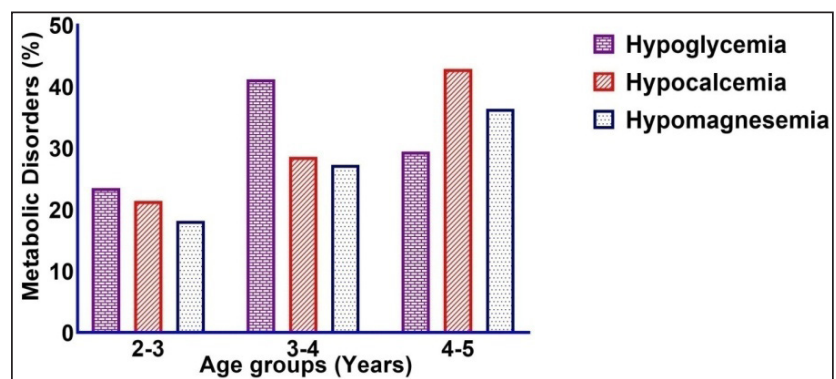

Fig. 4: Age group wise dissemination pattern of metabolic diseases in Hilly region goats of Uttarakhand

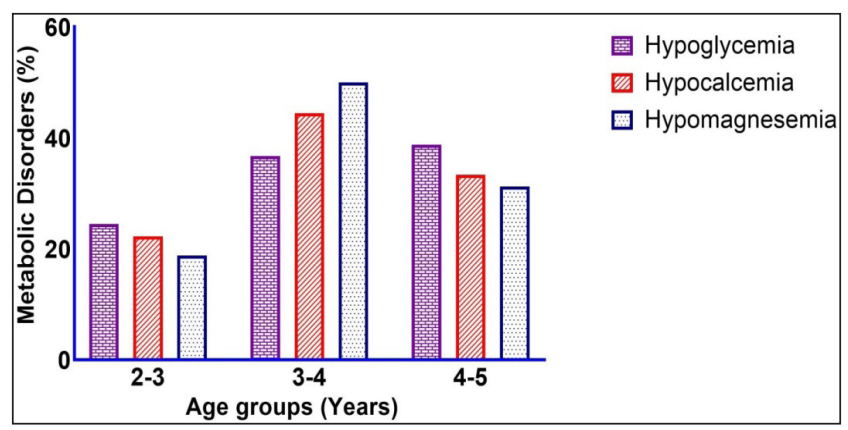

Fig. 5: Age group wise dissemination pattern of metabolic diseases in Tarai region goats of Uttarakhand

In case of hypocalcemic hilly region goats maximum occurrence $50.00 \%$ was sought among $3^{\text {rd }}$ parity goats followed by $35.71 \%$ among $2^{\text {nd }}$ parity goats and $14.28 \%$ among $1^{\text {st }}$ parity goats. Meanwhile in case of Tarai region goats maximum cases $(44.44 \%)$ were recorded among $3^{\text {rd }}$ parity goats followed by $(38.88 \%)$ among $2^{\text {nd }}$ parity goats and $16.66 \%$ in case of $1^{\text {st }}$ parity goats. However, the findings of the present study revealed that among hilly region goats, parity wise dissemination of hypomagnesaemia cases revealed maximum precipitation among $3^{\text {rd }}$ parity goats $(45.45 \%)$ followed by $2^{\text {nd }}$ parity goats $(36.36 \%)$ and $(18.18 \%)$ among $1^{\text {st }}$ parity goats. In case of Tarai region goats, maximum dissemination of hypomagnesaemia was recorded among $3^{\text {rd }}$ parity goats
$(50.00 \%)$ followed by $2^{\text {nd }}$ parity goats $(37.50 \%)$ and $1^{\text {st }}$ parity goats $(12.50 \%)$ respectively. The dissemination pattern of metabolic diseases in Hilly and Tarai region goats of Uttarakhand based on parity is graphically depicted in Fig. 6 and 7 respectively.

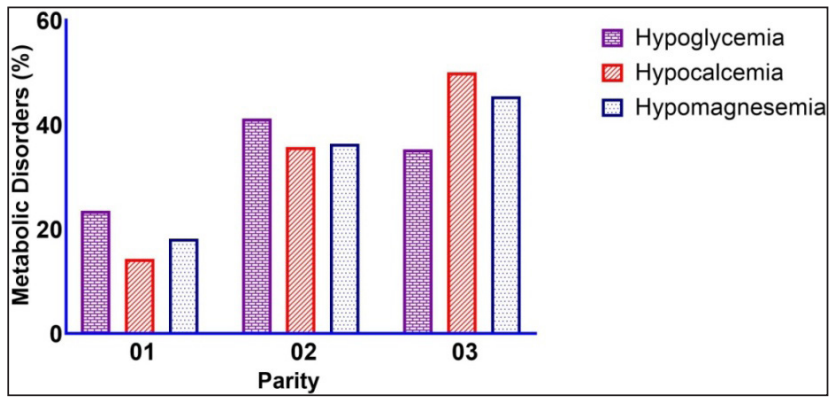

Fig. 6: Parity wise dissemination pattern of metabolic diseases in Hilly region goats of Uttarakhand

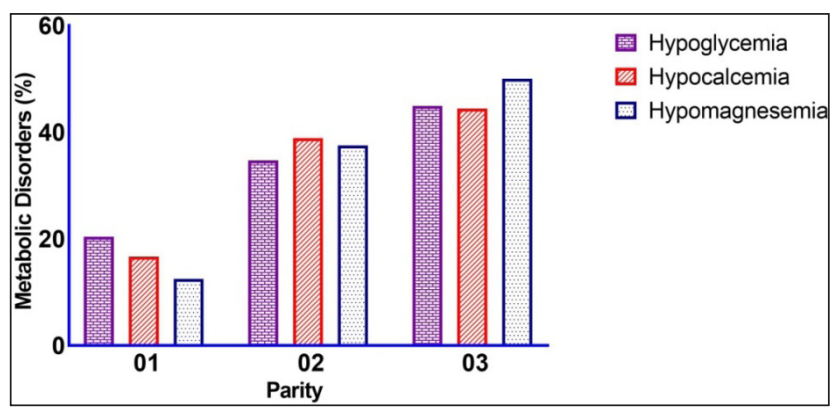

Fig. 7: Parity wise dissemination pattern of metabolic diseases in Tarai region goats of Uttarakhand

Animal husbandry practices are of prime importance since ancient time for the sustainability of the rural livelihood in the Indian scenario. Goatery is one of the important aspects of animal husbandry practices in Hilly and Tarai regions of Uttarakhand, where there is a scarcity of agriculture land. Beside this meagre work pertaining to highlighting the dissemination pattern of common metabolic ailments among goats was also one important factor to take this endeavour. The period around the kidding is considered as most challenging one, in a doe's reproductive phase. Various insults related to metabolic and nutritional prior, peri and post kidding, may lead to the initiation of key metabolic alterations significant to physiologic transition from pregnancy to lactation, resulting in innumerable metabolic ailments. Among goats hypocalcaemia, hypomagnesaemia and hypoglycemia /pregnancy toxemia 
are some common metabolic diseases whose precipitation is frequent. Pugh (2002) narrated that the severe weather conditions, predator attack and transportation (either by truck or by foot) may produce stress which, works as an important factor in the precipitation of the pregnancy toxaemia/ hypoglycemia in goats. The findings of the present study were endorsed by previous work of Radostits et al. (2007) whose result conveyed that in older age goats are more prone towards hypocalcaemia. The findings of the present study is also in corroboration with the previous explorative work performed by Radostits et al. (2007), narrated that as the age increases chance of precipitation of hypoglycemia/ketosis increases.

\section{CONCLUSION}

As we are well aware of the importance of animal husbandry practices in Indian scenario, among Hilly and Tarai region of Uttarakhand, under animal husbandry practices goatery is a common practice. Metabolic ailments are important among large ruminants as well as in small ruminants that's why retrospective inspection is an important aspect to apprehend its occurrence, so that preventive measures may take place in advance like supplementation of proper nutrition during transition phase, etc. in order to curb down the occurrence of various metabolic ailments and resulted financial losses successfully.

\section{ACKNOWLEDGMENTS}

The authors duly acknowledge to the DES, P.I. AICRP on Uttarakhand goat unit, Dean PGS, Dean, CVASc, GBPUAT, Pantnagar for providing necessary facilities to conduct this study under the Department of Veterinary Medicine. This work was funded by Co-ordinator, Tribal Sub Plan Project (Small Ruminant Sub-component) and also as $\mathrm{PhD}$ research grant to the first author by the GBPUAT, Pantnagar, Uttarakhand, India.

\section{REFERENCES}

Azab, M.E. and Abdel-maksoud, H.A. 1999. Changes some hematological and biochemical parameters during prepartum and postpartum periods in female Baladi goats. Small Rumin. Res., 34: 77-85.

Celi, P., Trana, A.D. and Quaranta, A. 2008. Metabolic profile and oxidative status in goats during the peripartum period. Aust. J. Exp. Agril., 48:1004-1008.
Drackley, J. 1999. Biology of dairy cows during the transition period: the final frontier. J. Dairy Sci., 82: 2259-2273.

Gupta, V.K., Sharma, S.D., Vihan, V.S. and Kumar, A. 2007. Influence of kidding seasons on prevalence of sub clinical ketosis in goats under organized farm condition. Indian $J$. Small Rumin., 13(2): 202-204.

Iriadam, M. 2007. Variation in certain hematological and biochemical parameters during the peri-partum period in Kilis does. Small Rumin. Res., 73: 54-57.

Ismail, Z. B, Al-Rawashdeh, O., Al-Majali, A.M. and Amireh, F. 2015. Prevalence and risk factors for pregnancy toxemia of goats in Jordan. ABAH Bioflux., 7(1): 53-59.

Lalitha, K., Rao, D.S.T. and Suryanarayana, C. 2001. Epizootiological studies on pregnancy toxemia in does. Indian Vet. Med. J., 25: 391-392.

Peter, R.D. and Peter, D.C. 2011. The Merck veterinary manual. $10^{\text {th }}$ Ed., Merck and Co., White House Station, New Jersey, USA, pp. 738-743.

Pugh, D.G. 2002. Sheep and Goat Medicine. $1^{\text {st }}$ Ed., W.B. Saunders, Philadelphia, pp. 97-99.

Radin, L., Simpraga, M.,Vince, S., Kostelic, A. and MilinkovikTur, S. 2015. Metabolic and oxidative status of Saanen goats of different parity during the peripartum period. J. Dairy Sci., 82: 426-433.

Radostits, O.M., Gay, C.C., Blood, D.C. and Hinchcliff, K.E. 2007. Veterinary Medicine: A text book of the diseases of cattle, sheep, goat, pig and Horses. $10^{\text {th }}$ Ed., Elsevier Saunders, London, pp. 1820-1821.

Ramin, A.G., Siamak, A.R. and Macali, S.A. 2007. Evaluation on serum glucose, BHB, urea and cortisol concentrations in pregnant ewes. Med. Weter., 63: 674 -677.

Rankins, D.L., Ruffin, D.C. and Pugh, D.G. 2002. Feeding and nutrition. In: Sheep and Goat Medicine. Pugh, D.G. $1^{\text {st }}$ Ed., WB Saunders, Philadelphia, pp. 48-50.

Roche, J.R., Dalley, D., Moate, P., Grainger, C., Hannah, M., O'Mara, F. and Rath, M. 2000. Variations in the dietary cation-anion difference and the acid-base balance of dairy cows on a pasture-based diet in south-eastern Australia. Grass Forage Sci., 55: 26-36.

Rook, J.S. 2000. Pregnancy toxemia of ewes, does and beef cows. Vet. Clin. North Am. Food Anim. Pract., 16: 293-317.

Rubino, R., Moioli, B., Fedele, V., Pizzillo, M. and MorandFehr, P. 1995. Milk production of goats grazing native pasture under different supplementation regimes in southern Italy. Small Rumin. Res., 17: 213-221.

Smith, M.C. and Sherman, D.M. 2009. Nutrition and metabolic diseases. In: Goat medicine, Smith, M.C., $2^{\text {nd }}$ Ed., WileyBlackwell, Lowa, pp. 733-785. 